\title{
Managed care for acute myocardial infarction survivors in the Silesian agglomeration during the COVID-19 pandemic
}

\author{
Katarzyna Wilkosz', Krystian Wita², Mariusz Gąsior³, Daniel Cieśla³ \\ 13.d Department of Cardiology, School of Medicine, Medical University of Silesia, Katowice, Poland \\ ${ }_{2}^{2} 1^{\text {st }}$ Department of Cardiology, School of Medicine, Medical University of Silesia, Katowice, Poland \\ ${ }_{3}^{33^{\text {rd }}}$ Department of Cardiology, School of Medical Sciences in Zabrze, Medical University of Silesia, Katowice, Poland
}

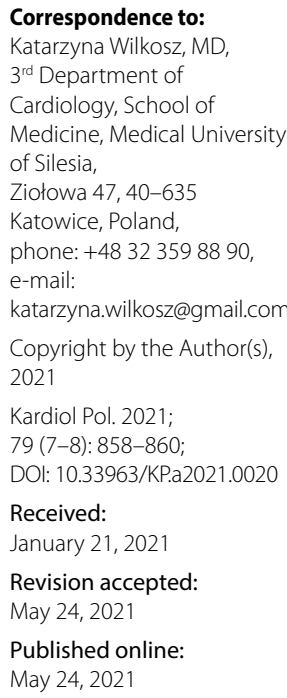

Correspondence to:

Katarzyna Wilkosz, MD, $3^{\text {rd }}$ Department of

Cardiology, School of

Medicine, Medical University of Silesia,

Ziołowa 47, 40-635

Katowice, Poland,

phone: +48 323598890 ,

e-mail:

katarzyna.wilkosz@gmail.com

Copyright by the Author(s),

2021

Kardiol Pol. 2021;

79 (7-8): 858-860;

DOl: 10.33963/KP.a2021.0020

Received:

January 21, 2021

Revision accepted:

May 24, 2021

Published online:

May 24, 2021

\section{INTRODUCTION}

Cardiovascular diseases, mainly acute coronary syndromes, are the most common cause of death in Poland. In order to improve the prognosis of patients after myocardial infarction, the Ministry of Health in cooperation with the National Health Fund introduced a program of the coordinated post-infarction care for acute myocardial infarction survivors (MACAMIS) in Poland (Polish KOS-zawał) [1]. Post-infarction rehabilitation begins within 14 days of discharge from the hospital. This rehabilitation occurs in either an inpatient ward or in a day rehabilitation unit after the end of the coronary revascularization stage (percutaneous coronary intervention, surgical coronary artery bypass graft, or hybrid treatment).Then, the annual plan of follow-up visits to the cardiology clinic was continued. During the annual follow-up, recommendations for secondary prevention of cardiovascular diseases are implemented, and the indications for electrotherapy (cardiac pacing, implantable cardioverter-defibrillator [ICD], or implantable cardiac resynchronization therapy defibrillator) are assessed [2].

During the COVID-19 pandemic, the number of hospitalizations due to acute coronary syndromes has decreased by around 45\% [3], and the percentage of percutaneous coronary angioplasty has been reduced [4]. Access to healthcare services, including rehabilitation centers, has also been significantly reduced. Before the announcement of a global pandemic, the number of centers implementing the MACAMIS program in Poland has started to gradually increase, most likely due to the confirmed effectiveness in improving the prognosis of patients who completed the program. In patients participating in the MACAMIS program, an almost $40 \%$ reduction of serious cardiovascular events was demonstrated at the one-year follow-up [5]. It has not yet been analyzed whether the SARS-CoV-2 pandemic had a significant influence on the number of participants in the program in the Silesian province.

\section{METHODS}

This analysis was based on data of the Polish National Health Fund, collected with SILCARD (Silesian Cardiovascular Database). It had been published elsewhere [5] and was based on the payer's data as per ICD-9 (procedures) and ICD10 (diagnoses), including all patients hospitalized in the cardiology, cardiac surgery, and vascular surgery departments. In addition, those diagnosed with cardiovascular diseases, as well as inpatients in internal disease and intensive care units (ICUs) across the Silesia province. The analyzed period includes patients enrolled in the MACAMIS program from October 2017 until July 2020. The before COVID group includes patients enrolled in the MACAMIS program from 20 October 2017 to 14 March $2020(n=9585)$. The COVID group includes patients enrolled in the MACAMIS program in the period from 15 March 2020 to 31 July $2020(n=1226)$. The groups are independent. The study protocol was approved by the Ethics Committee of the Medical University of Silesia in Katowice.

\section{Statistical analysis}

The distribution of quantitative variables was checked with the Shapiro-Wilk test, ant it was non-normal. Thus, nonparametric Mann-Whitney $\mathrm{U}$ tests were used, along with the Chisquare test with a correction for Yates discontinuity for qualitative variables. For the entire analysis, $P<0.05$ was considered significant. 
The calculations were performed with the data analysis software system, STATISTICA version 13 (TICBO Software Inc., Palo Alto, CA, USA).

\section{RESULTS AND DISCUSSION}

During the first wave of the COVID-19 pandemic (March-April 2020), the number of hospitalizations fot heart attacks in the Silesian region decreased by $43 \%$, as compared to the same period in 2019. Moreover, 360 patients were enrolled in the MACAMIS program in March 2019, with 405 patients in April 2019. During the same period in 2020, the corresponding numbers were 150 and 148 patients, respectively. Along with the reduction of the total number of patients in the MACAMIS program, the percentage of those hospitalized for heart attack significantly decreased from 36\% in March 2019 to $26 \%$ in March 2020 (Supplementary material, Figure S1). Patients treated under the MACAMIS program during the pandemic were older (median 65.7 vs 66.5 years; $P=0.014$ ), and less likely to have a history of chronic coronary syndrome $(42.59 \%$ vs $33.85 \%$; $P<0.001)$ and coronary angioplasty $(9.72 \%$ vs $6.28 \% ; P<0.01)$. More often, however, these conditions were accompanied by pulmonary edema during infarction (0.89\% vs $1.71 \% ; P=0.009)$ (Table 1$)$.

In the province of Silesia, for the first year of the MACAMIS program (i.e. 2018), the percentage of patients enrolled in the program after myocardial infarction was $36.7 \%$, approaching almost 50\% in the second half of 2019 [6]. During the first wave of the SARS-CoV-2 pandemic, this percentage decreased dramatically. Despite the initial slow increase in cases in Poland, large-scale screening for SARS-CoV-2 infection was carried out in Silesia, focusing on those working in mines and care homes. This led to the introduction of a number of restrictions, e.g. sanitary regulations and health measures to prevent infection in medical facilities also lowered the number of people hospitalized for cardiovascular disease - not only in Poland but throughout Europe [7]. According to the data of the National Health Fund, the possibility of treatment in cardiac rehabilitation departments was limited. According to the terms of the MACAMIS program, the early cardiac rehabilitation stage was mandatory: inability to start cardiac rehabilitation resulted in patient exclusion. On the other hand, for fear of being infected with SARS-CoV-2, patients did not agree to participate in the MACAMIS program.

The COVID-19 pandemic also led to significant limitations in routine services provided by the health care system. Preventive programs and vaccinations, as well as screening tests, were neglected [8]. This may have contributed to a worsening of the so-called "health deficit". The MACAMIS program was the first in Poland's multi-stage implementation of postinfarction care and secondary prevention of cardiovascular disease. Participation was associated with an almost $40 \%$ reduction in overall mortality, and a significant reduction in cardiovascular events after a one-year follow-up; the reduction trend in mortality persisted for subsequent follow-ups. Completion of cardiac rehabilitation and strict outpatient care were the main components of the MACAMIS program, contributing to mortality reduction [9].

Table 1. Baseline characteristics of both groups

\begin{tabular}{|c|c|c|c|}
\hline Variables & $\begin{array}{l}\text { Before COVID-19 } \\
\quad n=9585\end{array}$ & $\begin{array}{l}\text { During COVID-19 } \\
\qquad n=1226\end{array}$ & $P$-value \\
\hline Age, years, median (IQR) & $65.7(59.0-73.1)$ & $66.5(59.5-73.9)$ & 0.014 \\
\hline Female sex & 3124 (32.59) & $369(30.10)$ & 0.084 \\
\hline $\mathrm{CHD}$ & $4082(42.59)$ & $415(33.85)$ & $<0.001$ \\
\hline Previous MI & 8977 (93.66) & $1141(93.07)$ & 0.464 \\
\hline $\mathrm{HF}$ & $1195(12.47)$ & $174(14.19)$ & 0.096 \\
\hline Hypertension & $6472(67.52)$ & $805(65.66)$ & 0.202 \\
\hline Type II DM & $2771(28.91)$ & $326(26.59)$ & 0.097 \\
\hline $\mathrm{AF}$ & $748(7.80)$ & $108(8.81)$ & 0.241 \\
\hline Pulmonary edema & $85(0.89)$ & $21(1.71)$ & 0.009 \\
\hline COPD & $780(8.14)$ & $102(8.32)$ & 0.870 \\
\hline Asthma & $698(7.28)$ & $78(6.36)$ & 0.264 \\
\hline CKD & 421 (4.39) & $50(4.08)$ & 0.665 \\
\hline Cancer history & $2051(21.40)$ & $270(22.02)$ & 0.642 \\
\hline Stroke & $318(3.32)$ & $43(3.51)$ & 0.792 \\
\hline Pulmonary embolism & $53(0.55)$ & $8(0.65)$ & 0.814 \\
\hline Previous $\mathrm{PCl}$ & $932(9.72)$ & $77(6.28)$ & $<0.001$ \\
\hline Previous CABG & $99(1.03)$ & $6(0.49)$ & 0.094 \\
\hline PM & $89(0.93)$ & $12(0.98)$ & 0.988 \\
\hline$I C D$ & $54(0.56)$ & $4(0.33)$ & 0.388 \\
\hline CRT & $16(0.17)$ & $2(0.16)$ & 0.733 \\
\hline Dialysis & $49(0.51)$ & $5(0.41)$ & 0.788 \\
\hline
\end{tabular}

Data are presented as number (percentage) of patients unless otherwise indicated.

Abbreviations: $A F$, atrial fibrillation; $C A B G$, coronary artery bypass grafting; $C H D$, coronary heart disease; $C K D$, chronic kidney disease; COPD, chronic obstructive pulmonary disease; CRT, cardiac resynchronization therapy; DM, diabetes mellitus; $\mathrm{HF}$, heart failure; ICD, implantable cardioverter defibrillator; $\mathrm{MI}$, myocardial infarction; $\mathrm{PCI}$, percutaneous coronary intervention; PM, pacemaker 
Patients in the MACAMIS program were significantly older, which was related to fear of becoming infected during hospitalization in younger patients [10]. Older patients often manifested symptoms of pulmonary edema on admission, which may have resulted from extended time dealing with the infection, starting with the onset of stenocardial symptoms to coronary intervention [11]. Yet, patients included in the MACAMIS program had a less frequent history of confirmed coronary artery disease and coronary angioplasty. This may be explained by patients with multiple diseases that have a more severe course of myocardial infarction during the pandemic; increased mortality was reported in the literature [12].Coronary artery disease is an independent risk factor for poor prognosis during SARS-CoV-2 infection [13]. Restrictions in qualifications of inpatient rehabilitation departments did not allow for the inclusion of those with comorbidities in the MACAMIS program, which could have had an impact on subject characteristics.

There was a significant decrease in patients who qualified for the MACAMIS program during the first wave of the COVID-19 pandemic (March-April 2020). Along with proven effectiveness in reducing mortality and cardiovascular events in the annual follow-up, every effort was made to ensure that the MACAMIS program was not limited to only patients in the Silesian province, despite the current epidemiological situation.

\section{Supplementary material}

Supplementary material is available at https://journals. viamedica.pl/kardiologia_polska.

\section{Article information}

\section{Conflict of interest: None declared.}

Open access: This article is available in open access under Creative Common Attribution-Non-Commercial-No Derivatives 4.0 International (CC BY-NC-ND 4.0) license, allowing to download articles and share them with others as long as they credit the authors and the publisher, but without permission to change them in any way or use them commercially. For commercial use, please contact the journal office at kardiologiapolska@ptkardio.pl.

How to cite: Wilkosz K, Wita K, Gąsior M, et al. Managed care for acute myocardial infarction survivors in the Silesian agglomeration during the COVID-19 pandemic. Kardiol Pol. 2021; 79(7-8): 858-860, doi: 10.33963/KP.a2021.0020.

\section{REFERENCES}

1. Jankowski P, Gąsior M, Gierlotka M, et al. Coordinated care after myocardial infarction. The statement of the Polish Cardiac Society and the Agency for Health Technology Assessment and Tariff System [article in Polish]. Kardiol Pol. 2016; 74(8): 800-811, doi: 10.5603/KP.2016.0118, indexed in Pubmed: 27553352.

2. Gierlotka M, Zdrojewski T, Wojtyniak B, et al. Incidence, treatment, in-hospital mortality and one-year outcomes of acute myocardial infarction in Poland in 2009-2012--nationwide AMI-PL database. Kardiol Pol. 2015; 73(3): 142-158, doi: 10.5603/KP.a2014.0213, indexed in Pubmed: 25371307.

3. Gąsior M, Gierlotka M, Tycińska A, et al. Effects of the coronavirus disease 2019 pandemic on the number of hospitalizations for myocardial infarction: regional differences. Population analysis of 7 million people. Kardiol Pol. 2020; 78(10): 1039-1042, doi: 10.33963/KP.15559, indexed in Pubmed: 32820878.

4. Legutko J, Niewiara $\measuredangle$, Bartuś $S$, et al. Decline in the number of coronary angiography and percutaneous coronary intervention procedures in patients with acute myocardial infarction in Poland during the coronavirus disease 2019 pandemic. Kardiol Pol. 2020; 78(6): 574-576, doi: 10.33963/KP.15393, indexed in Pubmed: 32469190.

5. Wita K, Wilkosz K, Wita M, et al. Managed Care after Acute Myocardial Infarction (MC-AMI) - a Poland's nationwide program of comprehensive post-MI care - improves prognosis in 12-month follow-up. Preliminary experience from a single high-volume center. Int J Cardiol. 2019; 296: 8-14, doi: 10.1016/j.ijcard.2019.06.040, indexed in Pubmed: 31256995.

6. Gąsior M, Pres D, Wojakowski W, et al. Causes of hospitalization and prognosis in patients with cardiovascular diseases. Secular trends in the years 2006-2014 according to the SILesian CARDiovascular (SILCARD) database. Pol Arch Med Wewn. 2016; 126(10): 754-762, doi: 10.20452/pamw.3557, indexed in Pubmed: 27650214.

7. Clerkin KJ, Fried JA, Raikhelkar J, et al. COVID-19 and cardiovascular disease. Circulation. 2020; 141(20): 1648-1655, doi: 10.1161/CIRCULATIONAHA.120.046941, indexed in Pubmed: 32200663.

8. Elective surgery cancellations due to the COVID-19 pandemic: global predictive modelling to inform surgical recovery plans. British Journal of Surgery. 2020, doi: 10.1002/bjs.11746.

9. Wita K, Kułach A, Sikora J, et al. Managed care after acute myocardial infarction (MC-AMI) reduces total mortality in 12-month follow-up-results from a poland's national health fund program of comprehensive postmi care-a population-wide analysis. J Clin Med. 2020; 9(10): 3178, doi: 10.3390/jcm9103178, indexed in Pubmed: 33008030.

10. Black JRM, Bailey C, Przewrocka J, et al. COVID-19: the case for healthcare worker screening to prevent hospital transmission. Lancet. 2020; 395(10234): 1418-1420, doi: 10.1016/S0140-6736(20)30917-X, indexed in Pubmed: 32305073.

11. Mahmud E, Dauerman $\mathrm{H}$, Welt $\mathrm{F}$, et al. Management of acute myocardial infarction during the COVID-19 pandemic. J Am Coll Cardiol. 2020; 76(11): 1375-1384, doi: 10.1016/j.jacc.2020.04.039.

12. Barbieri L, Tumminello G, Lucreziotti $S$, et al. Mortality in STEMI patients during the COVID era: has the pandemic changed our clinical practice? Cardiovasc Revasc Med. 2021; 22: 120-121, doi: 10.1016/j. carrev.2020.09.014, indexed in Pubmed: 32958439.

13. Pawlak A, Dreżewski K, Szymański P, et al. Cardiovascular disease, therapy, and mortality of oligosymptomatic and symptomatic patients infected with SARS-CoV-2: experiences of a designated hospital in Poland. Kardiol Pol. 2020; 78(11): 1162-1165, doi: 10.33963/KP.15596, indexed in Pubmed: 32897038. 